\title{
Fórum de Coordenadores de Programas de Pós-Graduação em Educação (FORPREd/ANPEd): história, configurações, desafios
}

JOSÉ GONÇALVES GONDRA Universidade do Estado do Rio de Janeiro, Rio de Janeiro, RJ, Brasil

JOÃO BATISTA CARVALHO NUNES Universidade Estadual do Ceará, Fortaleza, CE, Brasil

MARCOS FRANCISCO MARTINS Universidade Federal de São Carlos, Sorocaba, SP, Brasil

RESUMO

Neste artigo analisamos o processo de constituição e configuração atual do Fórum de Coordenadores de Programas de Pós-Graduação em Educação (FORPREd) da Associação Nacional de Pós-Graduação e Pesquisa em Educação (ANPEd). Para tanto, trabalhamos com documentação oficial da ANPEd e elaboramos um questionário on-line, remetido via lista de discussão ao conjunto dos coordenadores e vice-coordenadores nela cadastrados. Com base nesses procedimentos e nas respostas ao referido instrumento, desenvolvemos uma reflexão em torno da organização desse coletivo, recobrindo aspectos de sua história, conformação atual e desafios apontados para consolidação e avanço da pesquisa e da pós-graduação em educação no Brasil. 


\title{
FORUM FOR GRADUATE PROGRAM COORDINATORS IN THE FIELD OF EDUCATION (FORPRED/ANPED): HISTORY, CURRENT CONFIGURATION, AND CHALLENGES
}

\begin{abstract}
In this article we analyzed how the Forum for Graduate Program Coordinators in the Field of Education (Fórum de Coordenadores de Programas de Pós-Graduação em Educação - FORPREd), which is part of the National Association for Graduate Research in Education (Associação Nacional de Pós-Graduação e Pesquisa em Educação - ANPEd), was developed, in addition to its current make-up. To do so, we worked with ANPEd official documentation and prepared an online questionnaire, which was sent to a mailing list containing a set of coordinators and vice-coordinators of the organization. Based on these procedures and the responses to the aforementioned instrument, we reflected on how the forum is organized, covering aspects of its history, current configuration, and challenges dealing with consolidation and the advancement of research and graduate education in Brazil.
\end{abstract}

KEYWORDS

ANPEd; FORPREd; graduate degree in education; education research.

\section{FORO DE COORDINADORES DE PROGRAMAS DE POSGRADO EN EDUCACIÓN (FORPRED/ANPED): HISTORIA, CONFIGURACIÓN, DESAFÍOS}

\section{RESUMEN}

En este artículo analizamos el proceso de constitución y configuración actual del Foro de Coordinadores de Programas de Posgrado en Educación (FORPREd) de la Asociación Nacional de Posgrado e Investigación en Educación (ANPEd). Para ello, trabajamos con documentación oficial de la ANPEd y elaboramos un cuestionario online, remitido vía lista de discusión al conjunto de los coordinadores y vicecoordinadores en ella registrados. Con base en esos procedimientos y en las respuestas al referido instrumento, desarrollamos una reflexión en torno a la organización de este colectivo, recobrando aspectos de su historia, conformación actual y desafíos apuntados para consolidación y avance de la investigación y del posgrado en educación en Brasil.

ANPEd; FORPREd; posgrado en educación; investigación en educación. 
Na Reunião Técnica que teve lugar em Belo Horizonte — 18 a 19/8/1994 — com a participação da diretoria da ANPEd, Coordenadores de Programas e Representantes do CNPq e da CAPES, foram definidas a organização e a estrutura do Fórum, como se segue:

a) Objetivos do Fórum

1. Servir como contato direto entre os coordenadores de Cursos de Pós-graduação.

2. Servir como fonte de conhecimento sobre políticas nacionais referentes à pós-graduação e sobre a atividade de Coordenação.

3. Servir para monitorar as agências que operam na área e encaminhar queixas e reivindicações.

b) A relação com a ANPEd

Foi determinado que o Fórum é uma parte integrantes da ANPEd, sendo ele uma reunião dos membros institucionais dessa Associação. Assim, os programas de Pós-graduação não formalmente filiados à ANPEd não serão considerados membros pelo Fórum. (Calazans, 1995, p. 52)

\section{INTRODUÇÃO}

De 14 a 16 de março de 1978, nas dependências da Fundação Getúlio Vargas (FGV), Rio de Janeiro, houve uma série de reuniões, oportunidade em que foi fundada a Associação Nacional de Pós-Graduação em Educação (ANPEd) ${ }^{1}$ (cf. Pucci, 2007). A ANPEd foi constituída como uma sociedade civil, sem fins lucrativos, que congrega instituições e profissionais de educação, no patamar de pós-graduação, com a finalidade de promover o desenvolvimento do ensino e da pesquisa. Durante a vigência da primeira diretoria, a ANPEd funcionou no prédio da FGV, situado à Praia de Botafogo n. 186, $3^{\circ}$ andar, na cidade do Rio de Janeiro. Tal fundação, contudo, foi precedida de um conjunto de agenciamentos, como consta no estudo realizado por Calazans (1995)².

A ANPEd foi criada em reunião organizada pelo IESAE/FGV no Rio de Janeiro, de 14 a 16 de março de 1978, com o apoio da CAPES. Estavam presentes à reunião 33 professores (alguns coordenadores) e alunos dos Programas de Pós-graduação em Educação; e representantes da CAPES, do CNPq, do INEP, da FINEP e do CNRH/IPEA. No total, 41 participantes do evento, conforme consta da Ata da Fundação.

1 A primeira diretoria da ANPEd foi composta por: Jacques Rocha Velloso - UnB (presidente), Newton Aquiles Von Zuben - Unicamp (vice-presidente), Maria Julieta Costa Calazans - FGV/IESAE (secretária-geral), Célia Frazão Soares Linhares UFF (secretária adjunta). As demais diretorias podem ser conferidas no site oficial da ANPEd: <www.anped.org.br>. Acesso em: 07 nov. 2016.

2 Documento distribuído na $18^{a}$ Reunião Anual da ANPEd, ocorrida em setembro de 1995, na Cidade de Caxambu, Minas Gerais. Na ocasião, a ANPEd era presidida pelo prof. Neidson Rodrigues (UFMG). 
Esta reunião foi antecedida de vários encontros em 1976 e 1977, cujo marco inicial foi a reunião de 19 a 20 de agosto de 1976, realizada na PUC/RJ, articulada pela CAPES e Coordenadores de Cursos de Pós-Graduação em Educação, com vistas a assegurar a organização da Associação Nacional de Pós-Graduação da área de Educação (associação de cursos, a exemplo de entidades já constituídas nas áreas de Economia e Administração). (Calazans, 1995, p. 11)

$\mathrm{O}$ ato fundacional contou com a participação de 17 programas $^{3}$. Decorridos cinco meses de instituída, foi realizada a $1^{\text {a }}$ Reunião Científica e Assembleia Geral da Associação Nacional de Pós-Graduação em Educação (ANPEd), nos dias 21, 22 e 23 de agosto de 1978, na sede da Universidade Federal do Ceará (UFC), com o objetivo de debater a "[...] concepção do Mestrado em Educação no Brasil, as diretrizes que fundamentavam os programas; experiências de ensino que vinham se consolidando e atendimento preferencial a diferentes clientelas" (Calazans, 1995, p. 19). A reunião destinou-se a todos os programas de pós-graduação em educação (PPGEs) ${ }^{4}$. Encontramos, aqui, portanto, a primeira referência a uma atividade que aglutinava os PPGEs e seus coordenadores.

Antes de prosseguir, cabe indagar quantos, onde e que cursos eram oferecidos em termos de formação pós-graduada. Neste texto, o foco consiste na modalidade stricto sensu, isto é, os cursos de mestrado e doutorado. Como é sabido, os três primeiros programas têm início na segunda metade dos anos de 1960, com os cursos de mestrado em educação, da PUC-RJ (1966) ${ }^{5}$, currículo, da UFSM (1967) ${ }^{6}$, e psicologia educacional, da PUC-SP $(1969)^{7}$. Na década seguinte (1970), temos a evolução explicitada no Quadro 1.

De acordo com Saviani (2000), os anos 1980 marcaram a redução do ritmo de abertura de novos programas. Segundo esse autor, de 1980 a 1983, não surgiram cursos de mestrado. No que se refere ao doutorado, há um lapso de sete anos, de 1983 a 1989, sem abertura de cursos, como podemos observar no Quadro 2, com seu retorno datado em 1990 (Quadro 3).

Em termos absolutos, evidenciamos um crescimento importante nas duas primeiras décadas da formação pós-graduada no Brasil, curva esta que se acentua nos anos 1990. Até fins dessa década, contabilizamos 47 programas de mestrado

3 FGV/IESAE, UFF, UFRJ, PUC-RJ, UnB, UNICAMP, PUC-SP, UFMS, UFRGS, $\mathrm{UFPb}, \mathrm{UFMG}$, UFC, UFPE, UFSC, UFPA, UFBA e PUC-RS.

4 A reunião contou com a participação dos coordenadores dos programas, representantes do INEP, CNPq, CNRH, CAPES, Secretaria-Geral do MEC e representantes do PICD da UFMA, da UFAM, da UFPE, da UFG, sócios efetivos e estudantes da ANPEd, bem como equipe técnica da FGV/IESAE responsável pela assessoria à Diretoria da ANPEd. Cf. Boletim ANPEd (1979).

5 Cf. site da PUC-Rio: <http://www.puc-rio.br/ensinopesq/ccpg/progedu.html>. Acesso em: 13 mar. 2017.

6 Cf. site da UFSM: < http://coral.ufsm.br/ppge/index.php/institucional/ppp>. Acesso em: 20 mai. 2017.

7 Cf. site da PUC-SP: <http://www.pucsp.br/pos-graduacao/mestrado-e-doutorado/ educacao-psicologia-da-educacao\#apresentacao >. Acesso em: 20 mai. 2017. 
e 18 de doutorado, o que ajuda a compreender a agenda da ANPEd voltada para enfrentar o debate doutrinário e político a respeito da pesquisa e da pós-graduação em educação, em curso desde que foi instituída a agremiação.

Em síntese, evidenciamos acelerado crescimento nos anos de 1970 quanto à formação pós-graduada no Brasil, pois saímos de apenas 3 cursos nos anos 1960 para 30 nos anos 1970, inclusive com a criação do primeiro doutorado em educação, em 1976 (PUC-RJ), representando um crescimento de 900\% no número de programas. Nos anos de 1980, o grau de crescimento foi menor, pois

Quadro 1 - Malha pós-graduada em educação no Brasil (1970-1979).

\begin{tabular}{|c|c|c|c|}
\hline Ano & Universidade & Programa & Curso \\
\hline 1971 & $\begin{array}{c}\text { USP } \\
\text { UFF } \\
\text { PUC-SP } \\
\text { FGV }\end{array}$ & $\begin{array}{c}\text { Educação } \\
\text { Educação } \\
\text { Filosofia da educação } \\
\text { Educação }\end{array}$ & $\begin{array}{l}\text { Mestrado } \\
\text { Idem } \\
\text { Idem } \\
\text { Idem }\end{array}$ \\
\hline 1972 & $\begin{array}{c}\text { UFMG } \\
\text { UFBA } \\
\text { UFRJ } \\
\text { UFRGS } \\
\text { PUC-RS } \\
\text { UNIMEP }^{8}\end{array}$ & $\begin{array}{c}\text { Educação } \\
\text { Idem } \\
\text { Idem } \\
\text { Idem } \\
\text { Idem } \\
\text { Idem }\end{array}$ & $\begin{array}{c}\text { Mestrado } \\
\text { Idem } \\
\text { Idem } \\
\text { Idem } \\
\text { Idem } \\
\text { Idem }\end{array}$ \\
\hline 1973 & USP & Ensino de ciências & Mestrado \\
\hline 1974 & UnB & Educação & Mestrado \\
\hline 1975 & $\begin{array}{l}\text { UNICAMP } \\
\text { PUC-SP }\end{array}$ & $\begin{array}{c}\text { Educação } \\
\text { Supervisão e currículo }\end{array}$ & $\begin{array}{l}\text { Mestrado } \\
\text { Idem }\end{array}$ \\
\hline 1976 & $\begin{array}{l}\text { UFSCAR } \\
\text { UFPR } \\
\text { PUC-RJ }\end{array}$ & $\begin{array}{l}\text { Educação } \\
\text { Educação } \\
\text { Educação }\end{array}$ & $\begin{array}{l}\text { Mestrado } \\
\text { Idem } \\
\text { Doutorado }\end{array}$ \\
\hline 1977 & $\begin{array}{c}\text { UFC } \\
\text { UFPB } \\
\text { USP } \\
\text { PUC-SP }\end{array}$ & $\begin{array}{c}\text { Educação } \\
\text { Educação } \\
\text { Educação } \\
\text { Filosofia da educação }\end{array}$ & $\begin{array}{l}\text { Mestrado } \\
\text { Idem } \\
\text { Doutorado } \\
\text { Idem }\end{array}$ \\
\hline 1978 & $\begin{array}{c}\text { UFRN } \\
\text { UFPE } \\
\text { UFES } \\
\text { UFSCAR } \\
\end{array}$ & $\begin{array}{c}\text { Educação } \\
\text { Educação } \\
\text { Educação } \\
\text { Educação especial } \\
\end{array}$ & $\begin{array}{l}\text { Mestrado } \\
\text { Idem } \\
\text { Idem } \\
\text { Idem } \\
\end{array}$ \\
\hline 1979 & $\begin{array}{c}\text { UERJ } \\
\text { PUC-SP }\end{array}$ & $\begin{array}{c}\text { Educação } \\
\text { Distúrbios da comunicação }\end{array}$ & $\begin{array}{l}\text { Mestrado } \\
\text { Idem }\end{array}$ \\
\hline \multicolumn{3}{|l|}{ Totais } & $\begin{array}{l}M=24 \\
D=03\end{array}$ \\
\hline
\end{tabular}

Fonte: elaboração própria, com suporte nos estudos de Calazans (1995),

Saviani (2000) e Pucci (2007), bem como consulta aos sites dos programas.

8 À época, Instituto Educacional Piracicabano. 
foram instituídos 14 cursos, enquanto nos anos de 1970 foram 27, significando um aumento de 46,7\% no quantitativo de cursos de um decênio para outro. Nos anos de 1990, a quantidade absoluta de cursos voltou a subir em comparação com a década anterior: foram 24 novos cursos, representando um crescimento de $54,5 \%$ no total de programas dos anos 1980 para os 1990 . Aportou-se a 1999 com um total de 68 cursos, sendo $50(73,5 \%)$ de mestrado e 18 (26,5\%) de doutorado (Gráficos 1 e 2).

Mantendo a curva ascendente observada até os anos de 1990, os anos seguintes também experimentam crescimento vertiginoso quanto ao volume da

Quadro 2 - Malha pós-graduada em educação no Brasil (1980-1989).

\begin{tabular}{|c|c|c|c|}
\hline Ano & Universidade & Programa & Curso \\
\hline 1980 & $\begin{array}{c}\text { UFRJ } \\
\text { UNICAMP }\end{array}$ & $\begin{array}{l}\text { Educação } \\
\text { Idem }\end{array}$ & $\begin{array}{l}\text { Doutorado } \\
\text { Idem }\end{array}$ \\
\hline 1982 & PUC-SP & Psicologia educacional & Doutorado \\
\hline 1984 & $\begin{array}{c}\text { UNESP - Rio Claro } \\
\text { UFSC }\end{array}$ & $\begin{array}{c}\text { Educação matemática } \\
\text { Educação }\end{array}$ & $\begin{array}{l}\text { Mestrado } \\
\text { Idem }\end{array}$ \\
\hline 1986 & $\begin{array}{c}\text { UCP - RJ } \\
\text { UFG } \\
\text { UNAERP - SP }\end{array}$ & $\begin{array}{l}\text { Educação } \\
\text { Idem } \\
\text { Idem }\end{array}$ & $\begin{array}{l}\text { Mestrado } \\
\text { Idem } \\
\text { Idem }\end{array}$ \\
\hline 1987 & UFAM & Educação & Mestrado \\
\hline 1988 & $\begin{array}{c}\text { CEFET-MG } \\
\text { UNESP - MARÍLIA } \\
\text { UFMT } \\
\text { UFMS }\end{array}$ & $\begin{array}{c}\text { Educação tecnológica } \\
\text { Educação } \\
\text { Idem } \\
\text { Idem }\end{array}$ & $\begin{array}{l}\text { Mestrado } \\
\text { Idem } \\
\text { Idem } \\
\text { Idem }\end{array}$ \\
\hline 1989 & USU - RJ & Educação matemática & Mestrado \\
\hline \multicolumn{3}{|l|}{ Total } & $\begin{array}{l}M=11 \\
D=03\end{array}$ \\
\hline
\end{tabular}

Fonte: elaboração própria.

Quadro 3 - Malha pós-graduada em educação no Brasil (1990-1999).

\begin{tabular}{|c|c|c|c|}
\hline Ano & Universidade & Programa & Curso \\
\hline 1990-1999 & & 12 mestrados & Mestrado \\
\hline 1990 & PUC-SP & Supervisão e currículo & Doutorado \\
\hline 1991 & $\begin{array}{l}\text { UFMG } \\
\text { UFSCAR }\end{array}$ & $\begin{array}{l}\text { Educação } \\
\text { Educação }\end{array}$ & $\begin{array}{l}\text { Doutorado } \\
\text { Idem }\end{array}$ \\
\hline 1992-1999 & & 9 doutorados & Doutorado \\
\hline \multicolumn{3}{|l|}{ Total } & $\begin{array}{l}M=12 \\
D=12\end{array}$ \\
\hline
\end{tabular}

Fonte: elaboração própria. 


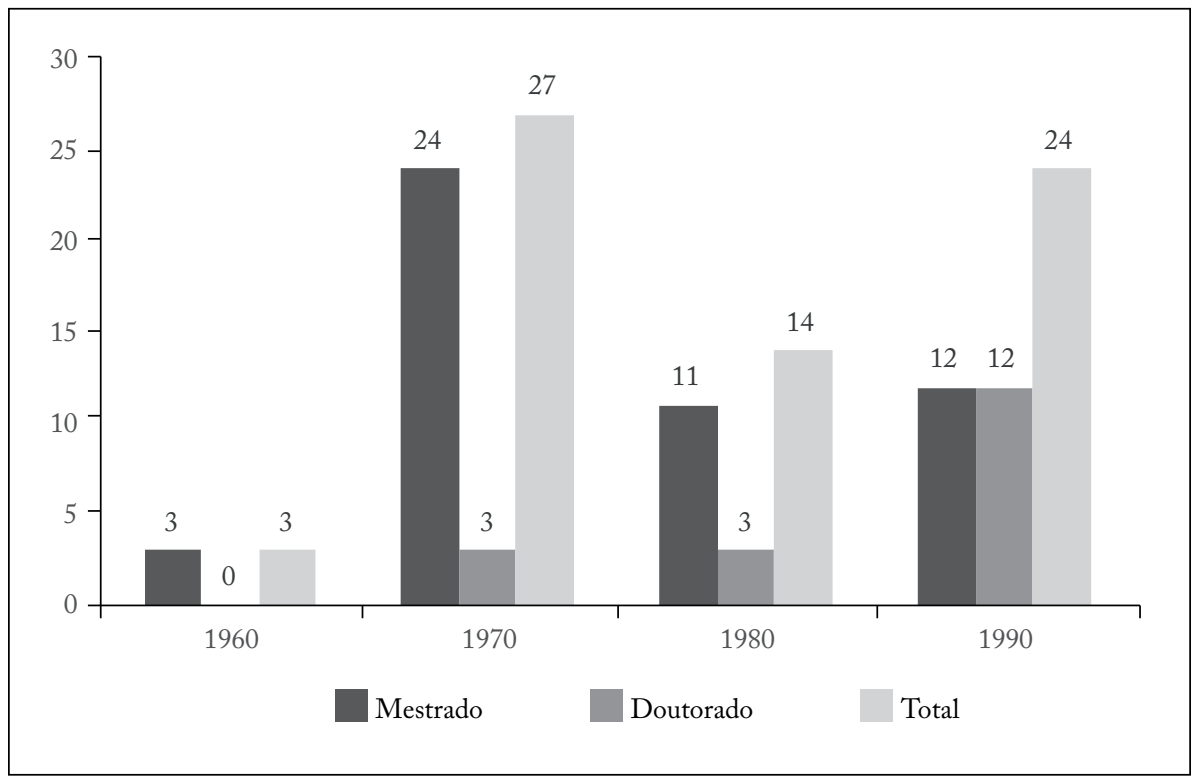

Gráfico 1 - Número de cursos de mestrado e doutorado criados nas décadas de 1960 a 1990.

Fonte: elaboração própria.

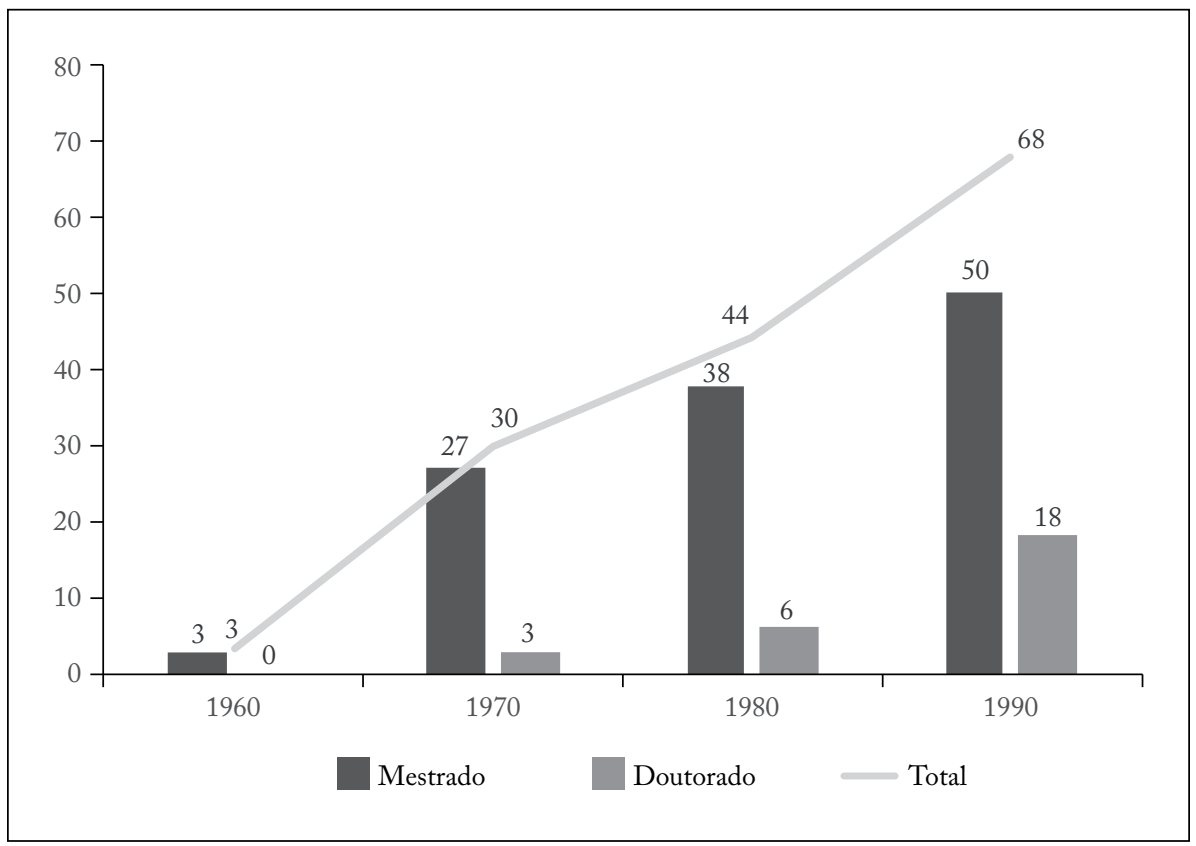

Gráfico 2 - Evolução na quantidade de cursos de mestrado e doutorado nas décadas de 1960 a 1990.

Fonte: elaboração própria. 
pós-graduação em educação. Até 2012, havia 124 programas na área. No último quadriênio, foram criados 48 , aumento de cerca de $38,7 \%$, o que corresponde, em média, à abertura de um programa por mês de 2013 a 2016 (Gráfico 3) ${ }^{9}$.

$\mathrm{O}$ fenômeno da expansão e do aparecimento de outras modalidades, como os mestrados profissionais, recoloca e atualiza o debate sobre a qualidade da formação e da pesquisa na área de educação, um ponto regular na pauta da ANPEd, que realiza mediações importantes nesse processo ao longo de sua trajetória.

Para enfrentamento das questões de ordem acadêmica, a entidade optou por uma estruturação em torno dos grupos de trabalho (GTs), após quatro anos de experiência, como consta no boletim de outubro de 1981 (Boletim Anped, 1981) ${ }^{10}$. Tal decisão foi tomada por ocasião da Assembleia Geral da Associação, realizada em Belo Horizonte, no dia 13 de março de 1981, esperando-se que os grupos constituíssem um fórum acadêmico importante para discussão e troca de opinião sobre: a) resultado de pesquisas realizadas; b) problemas relevantes que precisavam ser abordados em futuros trabalhos de pesquisa; c) experiências meto-

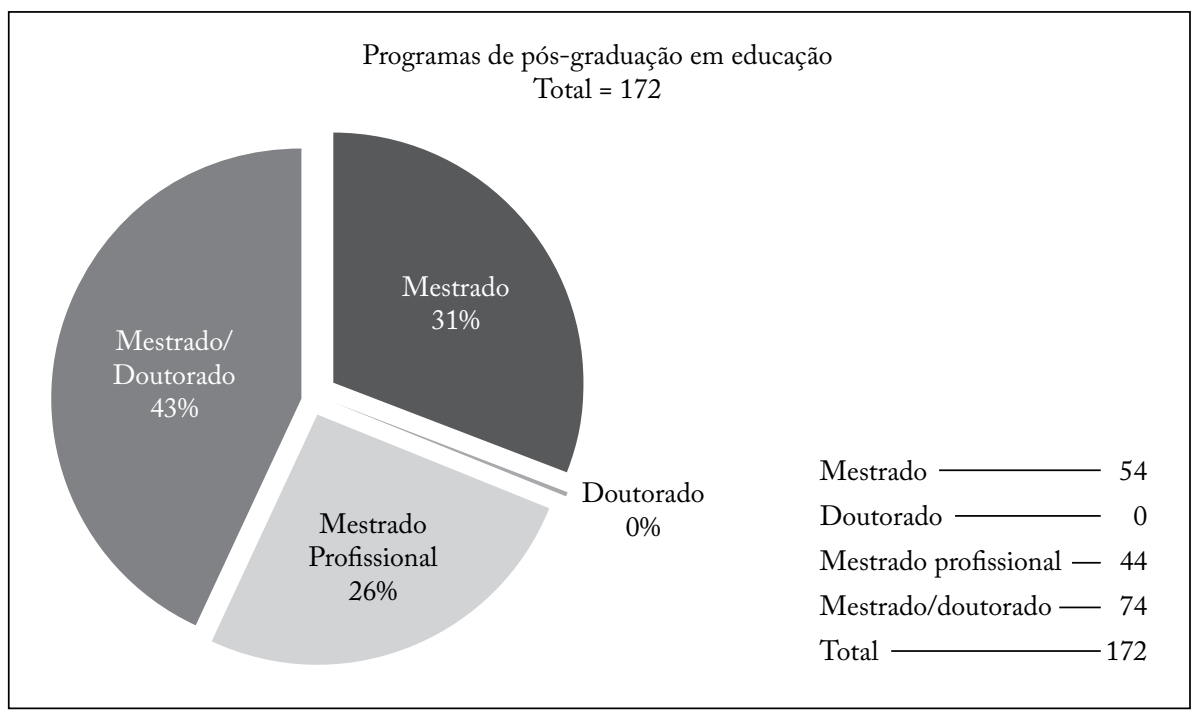

Gráfico 3 - Configuração atual da malha da pós-graduação em educação.

Fonte: Plataforma Sucupira, novembro de $2016^{11}$.

9 Não desconhecemos os processos de credenciamento adotados pela Coordenação de Aperfeiçoamento de Pessoal de Nível Superior (CAPES). A sinalização serve para demonstrar o crescimento vertiginoso nos últimos anos, mesmo sem considerarmos os documentos de apreciação de propostas de cursos novos (APCNs) apresentados em 2016. Tampouco levam em conta os projetos de Minter e Dinter, nacionais e internacionais. Juntos, tornam o incremento ocorrido ainda mais expressivo.

10 Os 20 boletins consultados circularam entre 1979 e 1990 . Cf. Anexo 1.

11 Cf. <https://sucupira.capes.gov.br/sucupira/>. Acesso em: 28 nov. 2016. 
dológicas; d) intercâmbio de informações bibliográficas; e) intercâmbio de estudos e trabalhos realizados ${ }^{12}$.

Se podemos considerar essa nova estrutura como uma resposta aos desafios expressos à qualidade da pesquisa e da formação, a política para criação, consolidação e aprofundamento da melhoria da qualidade dos programas implicou ações outras das Diretorias da ANPEd, como os temas do financiamento e da avaliação dos programas. No boletim de julho de 1985, focado na temática "ANPEd que temos, ANPEd que queremos", destacamos duas manifestações para sustentar o argumento anterior. No que se refere à avaliação dos programas de pós-graduação,

Questiona-se a natureza da avaliação dos cursos de pós-graduação nos termos em que esta vem sendo realizada pela CAPES. Propõe-se, em cada contrapartida, que o eixo catalizador da avaliação desses programas sejam os processos de avaliação interna dos próprios cursos. Vale ressaltar que esses processos devem ser articulados com a política de pós-graduação das respectivas universidades e desenvolvidos com a participação ampla das coordenações, professores e alunos dos cursos [...]. (Boletim ANPEd, 1985, v. 7, n. 4, p. 3)

Como se pode notar, a avaliação externa, com suporte em modelos estandardizados, é problematizada no veículo oficial da entidade desde o seu surgimento, sugerindo-se, alternativamente, um modelo centrado na experiência de cada instituição. Essa é uma tensão que marca o campo da educação, mas também está noutras áreas. Algo assemelhado se refere à problemática do financiamento dos programas de pós-graduação.

Propõe-se que a alocação de recursos para os programas de pós-graduação seja desvinculada dos resultados de um processo de avaliação formal - limitada nos seus termos uniformes e basicamente quantitativos - ou que, a curto prazo, pelo menos se atenuem os efeitos de tal avaliação na alocação dos recursos. (Boletim ANPEd, 1985, v. 7, n. 4, p. 4)

Aqui se observa outro ponto de tensão que perpassa a história da entidade. Nesse caso, a desvinculação do financiamento relativamente à avaliação se constitui matéria em torno da qual posições mais ou menos definidas se delineiam, recobrindo desde a tese da desvinculação plena até o argumento que defende a atenuação do vínculo entre esses dois elementos constitutivos do sistema de formação pós-graduada.

12 Os primeiros grupos foram coordenados por pesquisadores convidados pela Diretoria da ANPEd, considerando suas trajetórias na problemática do GT: Educação de 10 Grau - Guiomar Namo de Melo (ANDE-PUC-SP); Educação de 2o Grau Luiz Antonio Cunha; Educação Superior - Neidson Rodrigues e Laura da Veiga; Educação Popular - Osmar Fávero (IESAE/FGV) e Carlos Brandão (UNICAMP); Educação e Trabalho - Jacques R. Velloso (UnB); Educação para o Meio Rural Maria Julieta C. Calazans (IESAE/FGV); Educação e Linguagem - Magda Becker Soares (UFMG); e Educação Pré-escolar - Maria Malta Campos (FCC). 
Até então, inexistia uma orgânica maneira de articulação dos interesses dos programas, sendo estes absorvidos nas ações da diretoria e em atividades desenvolvidas nas reuniões anuais, em consórcio com agências de financiamento ou, ainda, entre programas. Segundo Pucci (2007, p. 428),

Osmar Fávero, como presidente da ANPEd, na sessão de abertura da 12a Reunião Anual (São Paulo, 1989), destaca como um dos pontos fortes da gestão do biênio 1985-1989, “a constituição do Fórum dos Coordenadores de Programas de Pós-Graduação, que tem se reunido sistematicamente no primeiro dia dos encontros anuais" (ANPEd, 1989, p. 85). Na verdade, o Fórum não tinha ainda sido criado formalmente, mas na prática já vinha atuando como tal, no interior da ANPEd.

A constituição formal do Fórum dos Coordenadores de Programas de Pós-Graduação em Educação se deu como uma consequência da "1a Reunião Técnica Nacional de Coordenadores de Programas de Pós-Graduação em Educação", realizada na Faculdade de Educação da Unicamp, de 1 a 12 de abril de 1991, convocada para discutir a política de pós-graduação e pesquisa. Durante o evento, os participantes formularam o documento "Política de pós-graduação e pesquisa em educação", "[...] primeiro documento coletivo dos coordenadores de programas" (Pucci, 2007, p. 428), no qual foram apresentadas conclusões e recomendações derivadas dessa reunião. Nele, os coordenadores indicaram a necessidade de se continuar discutindo quatro pontos: a) política de pós-graduação e pesquisa; b) avaliação dos PPGEs; c) relação entre ANPEd, programas de pós-graduação e órgãos governamentais e suas agências; d) articulação entre programas de pós-graduação, grupos de trabalho e a própria ANPEd.

Em 1992, quando da 15a Reunião Anual da ANPEd (RA) ${ }^{13}$, realizada em Caxambu, os coordenadores debateram três pontos articulados aos encaminhamentos da $1^{\text {a }}$ Reunião Técnica. Na oportunidade, foi convocada, pela Diretoria da ANPEd, a 2a Reunião Técnica dos Coordenadores para o primeiro semestre de 1993. Ocorrida na UFMG, em abril de 1993, "foi durante sua realização que se deu a criação do Fórum, mesmo não constando tal fato da pauta da reunião" (Pucci, 2007, p. 429) ${ }^{14}$.

A genealogia dessa entidade pode ser compreendida na chave que articula uma avaliação do que se processava no campo da educação, com sinais de uma expansão importante, associada aos desafios decorrentes desse novo quadro, tendo em vista uma ação mais concertada por parte dos programas. Como assinala $\mathrm{Ca}-$ lazans $(1995$, p. 51),

13 Até a 35a , ocorrida em 2012, esse evento acontecia anualmente e recebia a denominação de Reunião Anual da ANPEd. A partir de 2013, o evento passou a ser denominado de Reunião Nacional da ANPEd e sua periodicidade foi alterada para bienal.

14 O FORPREd pode ser caracterizado em torno de seus nomes. Inicialmente era uma reunião de coordenadores. No segundo momento, assumiu a configuração de um Fórum da Educação, o Eduforum, para, posteriormente, assumir a designação atual. Não localizamos a reunião em que essas mudanças foram efetivadas. 
A necessidade de um Fórum específico para essa discussão foi determinada pelo fato de não se poder ignorar que, após mais de 20 anos de estabelecimento dos cursos de PG no Brasil e da sua crescente expansão, tornou-se imperativa uma avaliação desse mesmo processo de expansão e de se dimensionar a direção que a própria pressão social, os novos paradigmas emergentes e as necessidades históricas colocam como desafios para os Programas e para as Universidades brasileiras hoje.

A agenda do fórum assumia pontos relativos a "natureza" da pós-graduação, institucionalização e exigências da especialização, grau de exigência dos cursos de mestrado e doutorado, relação com agências de fomento, articulação e relacionamento entre os programas e os departamentos das instituições de educação superior (IESs) e suas pró-reitorias, relações nacionais e internacionais, relações interprogramas e sistemas de informação e de bibliotecas. A respeito do modelo, a recusa ao formato GT foi fundamentada em um duplo argumento (cf. Pucci, 2007, p. 429-430). Como fórum, o encontro seria aberto a todas as pessoas interessadas em participar da discussão dos rumos da pós-graduação, independentemente de qualquer vinculação formal a um programa específico. O segundo indicava a agenda própria no interior da reunião da ANPEd, o que não deveria impedir a participação dos coordenadores em GTs vinculados aos interesses da pauta do fórum ${ }^{15}$.

$\mathrm{Na} 3^{\text {a }}$ Reunião Técnica, ocorrida em Belo Horizonte, nos dias 18 e 19 de agosto de $1994^{16}$, se procedeu à primeira regulamentação do fórum e de seu funcionamento. Aconteceu uma codificação em torno de cinco núcleos:

1. Objetivos;

2. Relação com a ANPEd;

3. Recursos financeiros;

4. Periodicidade e época;

5. Mandato do coordenador e vice-coordenador ${ }^{17}$.

Convencionadas as configurações gerais de funcionamento, dois meses depois, na Reunião Anual ocorrida em outubro de 1994, em Caxambu, o fórum reafirmou compromissos programáticos que vinham sendo delineados em torno de uma pauta que recobria a preocupação com a política de bolsas da Coordenação de Aperfeiçoamento de Pessoal de Nível Superior (CAPES), a eleição para o Comitê Científico da ANPEd e a implantação da "Rede ANPEd ${ }^{18}$ ". Por fim, Calazans (1995) reforça a ideia de que o fórum estava atuando como um instrumento para melhoria da produção científica da área, bem como para o estabelecimento

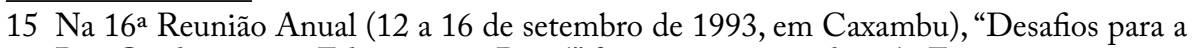
Pós-Graduação em Educação no Brasil” foi o tema assumido pelo Fórum.

16 Contou com a participação da Diretoria da ANPEd, de coordenadores de programas e de representantes do CNPq e da CAPES.

17 Para um detalhamento dessa regulamentação, cf. Calazans (1995, p. 52-53).

18 Nos documentos consultados, não encontramos esclarecimento a respeito do que seria essa "Rede". 
de uma política de pós-graduação em educação no Brasil, discutindo a especialização, a expansão dos cursos de doutorado, que, até 1990, como indicado nos Quadros 1, 2 e 3, totalizavam seis, concentrados no Rio de Janeiro e em São Paulo. Atuava igualmente na definição das exigências relativas às dissertações e às teses, na incorporação de novos docentes-pesquisadores e de relações internacionais e com as agências de fomento.

A primeira eleição dos representantes regionais do Fórum de Coordenadores de Programas de Pós-Graduação em Educação (FORPREd) ${ }^{19}$ ocorreu na $3^{a}$ reunião do fórum, realizada durante a 18a Reunião Anual da ANPEd, em 1995. Além disso, nessa reunião $\left(3^{\mathrm{a}}\right)$, os coordenadores reivindicaram assento na Diretoria da ANPEd e que, no estatuto da entidade e no organograma, o FORPREd pudesse ser considerado como uma instância da associação. Essa reivindicação se consolidou posteriormente, mas com um histórico de tensionamentos localizados entre o FORPREd e a Diretoria da ANPEd, marcados, sobretudo, por certos desentendimentos em relação aos limites e às possibilidades dessa vinculação, evidenciável na dupla indagação: o FORPREd tem autonomia em relação à Diretoria da ANPEd, inclusive para dialogar diretamente com a CAPES e agências de fomento? Ou o FORPREd é uma extensão da Diretoria, sem autonomia?

Controvérsias como essas mediaram e medeiam o debate, que ainda hoje parece ser algo não tão bem entendido por alguns sujeitos desse processo, que precisaram e precisam, ainda, equalizar outro complicador, que é o do papel do representante de área junto à CAPES:

[...] evidenciava-se a difícil e ambígua posição do representante da área junto à CAPES. Ele é o representante indicado pela área, em contínua interação com ela; e, ao mesmo tempo, aquele que deve seguir, na avaliação, os critérios rigidamente estabelecidos pela agência governamental, com espaços limitados de intervenção em um sistema avaliador-coercitivo. (Pucci, 2007, p. 434)

De acordo com Pucci (2007), no período de 1996 a 2002, enfrentando essas dificuldades, o FORPREd amadureceu a relação com a associação e com a representação de área na CAPES, do que resultou, em 2002, no Rio de Janeiro, a apresentação da primeira proposta de regimento, aprovada na 25a Reunião Anual da ANPEd. Segundo o regimento, o FORPREd tem autonomia relativa da Diretoria da ANPEd, como articular-se com a representação de área e buscar diálogos com as agências de fomento para otimizar os recursos necessários à pesquisa em educação.

A pauta inicial do fórum parece ter se tornado complexa desde então, considerando a expansão, o refinamento da matriz de avaliação externa, a constituição de uma rede de fundações de amparo à pesquisa (FAPs), a luta por legitimidade

19 "As primeiras representações regionais assim se instituíram com seus respectivos coordenadores: região Norte (Mirian Trindade Garret -UFAM); região Nordeste: (Edivaldo Boaventura - UFBA); região Sul (Nilton Fischer - UFRGS); região Sudeste 1/SP (Alípio Casali - PUC-SP); região Sudeste 2/RJ, MG, ES (Antônio Flávio Barbosa de Oliveira - UFRJ); região Centro-Oeste (Eurize Pessanha - UFMS)" (Pucci, 2007, p. 431). 
da produção de conhecimento qualificado, os agenciamentos internos das universidades, faculdades e agremiações científicas, bem como as apostas em projetos de internacionalização e de combate às diversas assimetrias e desigualdades, tanto no plano nacional como na escala transnacional.

Para se comprovar a configuração da malha pós-graduada, cabe observar o que se processou ao longo das duas últimas décadas, considerando os programas vinculados à área de educação da CAPES:

- 2007 - 78 programas;

- 2010 - 94 programas;

- 2013 - 121 programas, sendo 9 de mestrados profissionais (MPs);

- 2016 (novembro) - 172 programas, sendo 44 de MPs.

Há de se considerar, ainda, a constituição da área de ensino no interior da CAPES, que passou a abrigar programas inicialmente inseridos na área de educação ${ }^{20}$. Ao lado disso, há de se notar a existência de alguns programas vinculados à grande área interdisciplinar da CAPES ${ }^{21}$, com participação regular no âmbito da ANPEd ${ }^{22}$.

Com base nesses elementos, um aspecto parece que ainda não foi suficientemente explorado. Afinal, constituído o fórum com os sócios institucionais da ANPEd, ainda carecemos compreender quem são os coordenadores dos PPGEs no país e o que pensam sobre o papel do FORPREd. Que sujeitos, homens e mulheres, exerciam (e exercem) a função de coordenação dos programas e do próprio fórum? ${ }^{23}$ Que formação possuíam? Que experiência prévia os habilitava para o exercício dessa função, considerada estratégica na organização da pós-graduação e na própria estrutura da ANPEd? Como percebiam a posição ocupada e as mediações a ela correlatas? Para responder a esse inquérito, passamos a explorar aspectos centrais do questionário elaborado pelos autores deste artigo e distribuídos aos integrantes da lista do FORPREd de dezembro de 2015 a fevereiro de 2016. Ao lado do valor da informação derivada dessas interrogações, ela pode cumprir uma função estratégica para o delineamento de ações no FORPREd, no contexto nacional ou regional sendo esta uma das lacunas que este texto visa a preencher.

20 Cf. <http://capes.gov.br/component/content/article/44-avaliacao/4670-ensino>. Acesso em: 13 mar. 2017.

21 Cf. <http://capes.gov.br/component/content/article/44-avaliacao/4674-interdisciplinar>. Acesso em: 13 mar. 2017.

22 Cabe ainda considerar a inexistência de uma árvore do conhecimento compartilhada por toda a comunidade acadêmica, expressão de que a classificação implica definição de domínios e possibilidades de se obter legitimidade, reconhecimento, prestígio, recursos e outros benefícios materiais e simbólicos. Uma demonstração deste não compartilhamento pode ser observada no modo como as áreas se encontram organizadas na CAPES e no CNPq, para ficarmos no plano nacional. A fim de aprofundar a reflexão, dever-se-ia observar a taxonomia do campo científico empregada pelas fundações estaduais de amparo à pesquisa e pelas universidades, do Brasil e do exterior, por exemplo.

23 Uma relação das coordenações do FORPREd pode ser conferida no Anexo 2. Neste artigo, os sujeitos que integram as coordenações nacionais e regionais do FORPREd não foram objeto de estudo. Um trabalho com estes agentes, bem como com as presidências e diretorias da ANPEd, ainda está por ser feito. 
A pesquisa que dá sustentação à segunda parte deste artigo investiu em produzir um perfil dos coordenadores que participam do FORPREd, conhecer a percepção que os coordenadores possuem deste, bem como identificar propostas para sua configuração e suas ações. Em decorrência desses objetivos, delineamos a metodologia, descrita na próxima seção.

\section{METODOLOGIA}

Considerando os objetivos propostos, empregou-se o que é denominado na literatura como modelo misto de pesquisa (mixed model research), ao procurar integrar procedimentos quantitativos e qualitativos dentro e ao longo dos estádios da investigação ${ }^{24}$ (Johnson e Christensen, 2003).

Aplicou-se, pois, o survey como método de pesquisa, dada a necessidade principal de descrever o fenômeno relativamente a uma população. Foi eleito como desenho básico o survey interseccional, que possibilita caracterizar uma população com amparo numa amostra em um determinado momento (Babbie, 1999).

O Estatuto da ANPEd, em seu art. 25, estabelece que o FORPREd "[...] é uma instância permanente de organização dos associados institucionais da ANPEd." (ANPED, 2012, art. 25). O FORPREd, contudo, acolhe todos os coordenadores e vice-coordenadores de PPGEs, independentemente se seus programas são ou não associados institucionais da ANPEd, embora o direito de votar e ser votado seja garantido exclusivamente aos associados.

A população foi constituída, por conseguinte, pelo conjunto de coordenadores e vice-coordenadores dos PPGEs em funcionamento em 2015 no Brasil - inscritos na lista de discussão do FORPREd. Nesse ano, havia 161 programas, sendo 58 somente mestrados acadêmicos, 36 mestrados profissionais e 67 mestrados acadêmicos e doutorados. Considerando a constante rotatividade de professores ocupando o ofício de coordenação ${ }^{25}$ e a diversidade de configurações possíveis na gestão dos programas, que pode ter apenas coordenador, coordenador e vice-coordenador ou um grupo gestor (Bianchetti, 2009), optamos por considerar, para efeito de cálculo, a situação mais comum de dois integrantes - coordenador e vice-coordenador. Desse modo, a população alcançou o número de 322 sujeitos.

Adotamos amostragem aleatória simples para esse conjunto de sujeitos, com intervalo de confiança de $95 \%$, estimativa de proporção populacional de

24 Segundo Johnson e Christensen (2003), há dois tipos de modelos mistos de pesquisa: dentro dos estádios da pesquisa (within-stage), mediante a combinação de abordagens quantitativas e qualitativas dentro de um ou mais estádios da investigação (por exemplo, quando se usa um questionário com perguntas abertas e fechadas); ou ao longo dos estádios da pesquisa (across-stage), quando abordagens quantitativas e qualitativas são misturadas ao longo de, no mínimo, dois estádios da investigação (por exemplo, ao se usar objetivos de natureza qualitativa e procedimentos de coleta de dados quantitativos).

25 Cada instituição define o mandato e o período de eleição ou indicação da coordenação. Ademais da alternância de pessoas na função de coordenação conforme o previsto nos regimentos dos programas, deve-se considerar os casos motivados por falecimento, afastamento por doença, entre outras situações. 
0,5 e erro amostral inicial de 0,05. Esperávamos obter uma amostra estimada de 175 participantes. A taxa de resposta do instrumento enviado, contudo, alcançou $46,3 \%$ (81 respondentes), o que nos levou a redefinir o erro amostral para 0,0943.

O instrumento utilizado foi um questionário on-line com 54 perguntas fechadas e abertas, criado na ferramenta "Formulários Google" (Wright, 2005). Antes da aplicação do questionário aos sujeitos participantes da pesquisa, realizou-se sua validação junto às cinco coordenações regionais do FORPREd, a fim de identificar a necessidade de possíveis acréscimos, correções ou clarificações na elaboração dos quesitos.

Como o FORPREd mantém uma lista de discussão, da qual, a princípio, participam todas as coordenações dos PPGEs do país, foi enviado um e-mail para essa lista, solicitando a colaboração de todos para preencher o questionário on-line em 21 de dezembro de 2015, indicando o link para o referido instrumento. Novo pedido de colaboração foi enviado por e-mail em 02 de fevereiro de 2016. O prazo para responder encerrou-se em 29 de fevereiro de 2016.

Analisamos os itens fechados do questionário on-line, recorrendo a técnicas estatísticas e apresentação gráfica, por meio do software de análise estatística Stata e da planilha eletrônica Excel (Babbie, 1999; Fávero et al., 2014). Nos itens abertos, empregamos a Análise de Conteúdo clássica (Bauer, 2002).

Embora o instrumento solicitasse a identificação dos respondentes, a fim de verificarmos apenas se havia coordenador ou vice-coordenador em atividade, os dados foram organizados e analisados sem a identificação dos sujeitos, preservando-lhes o anonimato.

\section{O ATUAL PERFIL DOS COORDENADORES DOS PROGRAMAS DE PÓS-GRADUAÇÃO EM EDUCAÇÃO}

O questionário on-line foi respondido por 81 pessoas: 86,42\% (70) são coordenadores e $13,58 \%$ (11) são vice-coordenadores de PPGEs, desde agora denominados "membros de coordenação". Referendada a feminização do magistério, em especial na seara educacional, a maioria é constituída pelo gênero feminino $(60,49 \%)$. O restante é do gênero masculino $(38,27 \%)$ ou não respondeu $(1,23 \%)$.

Do total de respondentes, 95,06\% (77) informaram a idade. Observamos grande variação quanto a essa característica dos sujeitos. O de menor idade tem 36 anos, e o de maior, 77, mais do dobro do menor valor do conjunto, representando uma amplitude de 41 anos. A média aritmética da idade é de 51,43 anos, com um desvio-padrão de 7,76 anos. Metade dos membros de coordenação possui até 52 anos (Gráfico 4).

Quanto à raça/etnia, 70,37\% (57) se consideram brancos, 8,64\% (7) pardos, $4,94 \%$ (4) negros e $1,23 \%$ (1) mestiço. Os demais membros de coordenação não responderam $(8,64 \%)$ ou consideraram não possuir raça definida $(1,23 \%)$, nenhuma raça ou etnia $(3,70 \%)$ ou não consideraram essa pergunta pertinente $(1,23 \%)$.

Os programas nos quais os respondentes atuam se localizam em todas as Regiões do Brasil, com destaque para Sudeste (35,80\%) e Sul (24,69\%), que, juntas, respondem por mais da metade desses programas. Os demais estão situados no Nordeste $(17,28 \%)$, no Centro-Oeste $(14,21 \%)$ e no Norte $(6,17 \%)$. Apenas uma 
pessoa $(1,23 \%)$ preferiu não explicitar a região de seu programa. São programas, segundo as respostas obtidas, que se encontram, em sua maioria (90,12\%), na situação de associados institucionais da ANPEd.

Se 73 membros de coordenação assinalaram que seus programas são associados institucionais da ANPEd, somente 60 informaram o ano de filiação. Constatamos que esse dado tem grande variação: há desde programas que se filiaram em $1970^{26}$ até os que o fizeram em 2015. Segundo as respostas obtidas, metade se filiou antes de 2006. A outra metade o fez de 2007 a 2015, durante os últimos nove anos. Isso indica que o crescimento das filiações de PPGEs à ANPEd acelerou nos últimos anos.

Os resultados referentes aos programas em que atuam os respondentes devem ser tomados com cuidado, pois podem representar informação duplicada, nas situações em que o coordenador e o vice-coordenador do mesmo programa tiverem preenchido o questionário.

De modo similar à idade dos respondentes, também se pode observar grande variação no ano de conclusão do doutorado. Os membros de coordenação obtiveram seus títulos de doutor de 1985 até 2013 (Gráfico 5). Aproximadamente metade (50,62\%) destes se tornou doutor de 1985 até 2004, um período de 20 anos, e o restan-

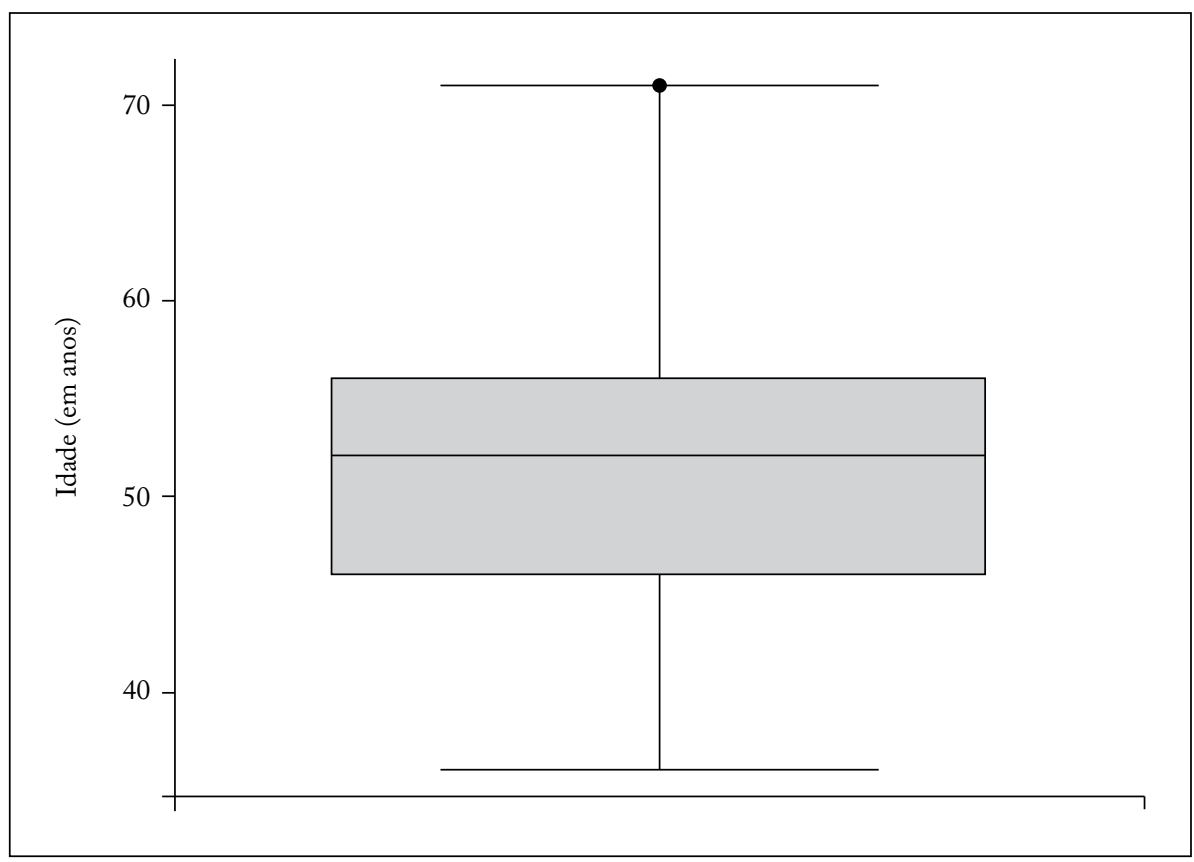

Gráfico 4 - Idade dos membros de coordenação (2016).

Fonte: Elaboração própria.

26 Registramos imprecisão nessa informação, porquanto o Eduforum/FORPREd, como uma instância da ANPEd, foi instituído em 1993. 
te, de 2005 até 2013, perfazendo 9 anos. Há quatro casos atípicos (outliers), cujos anos de conclusão foram 1985, 1987, 1988 e 1990. Esse resultado mostra que existe uma quantidade expressiva de jovens doutores assumindo as coordenações dos PPGEs.

O número de membros de coordenação com doutorado fora do país é pequeno. Somente 4 respondentes $(4,93 \%)$ cursaram doutorado no estrangeiro, limitando-se a países da Península Ibérica (Espanha - 3,70\% - e Portugal - 1,23\%), distribuídos por três universidades: Universidade Autônoma de Barcelona (UAB), Universidade de Santiago de Compostela (USC) e Universidade do Porto (UP).

Os demais respondentes concluíram o doutorado no Brasil $(95,06 \%)$. Cinco universidades formaram pouco mais da metade $(54,32 \%)$ desses doutores: USP (14,81\%), PUC-SP (12,35\%), Unicamp (12,35\%), UFRGS (9,88\%) e Unisinos (4,94\%). São IESs localizadas apenas nos estados de São Paulo (USP, PUC-SP e Unicamp) e Rio Grande do Sul (UFRGS e Unisinos). As outras universidades estão, segundo a quantidade, nas regiões: Sudeste (UFF, UNESP, PUC-Rio, UFMG, UFSCar, UNIMEP, PUC-Campinas, UERJ, UFLA, UFRJ e UNESP), Nordeste (UFBA, UFC, UFPE e UFPB), Sul (UFSC, PUC-RS e UFPR) e Centro-Oeste (UFG e UnB). Nenhum respondente foi formado em uma IES da região Norte.

Menos da metade $(46,91 \%)$ dos membros de coordenação fez estágio de pós-doutorado (Gráfico 6). O ano de conclusão do pós-doutorado variou de 2002 a 2015. Dos 38 respondentes que realizaram pós-doutorado, metade concluiu de 2002 a 2011, enquanto a outra metade finalizou de 2012 a 2015.

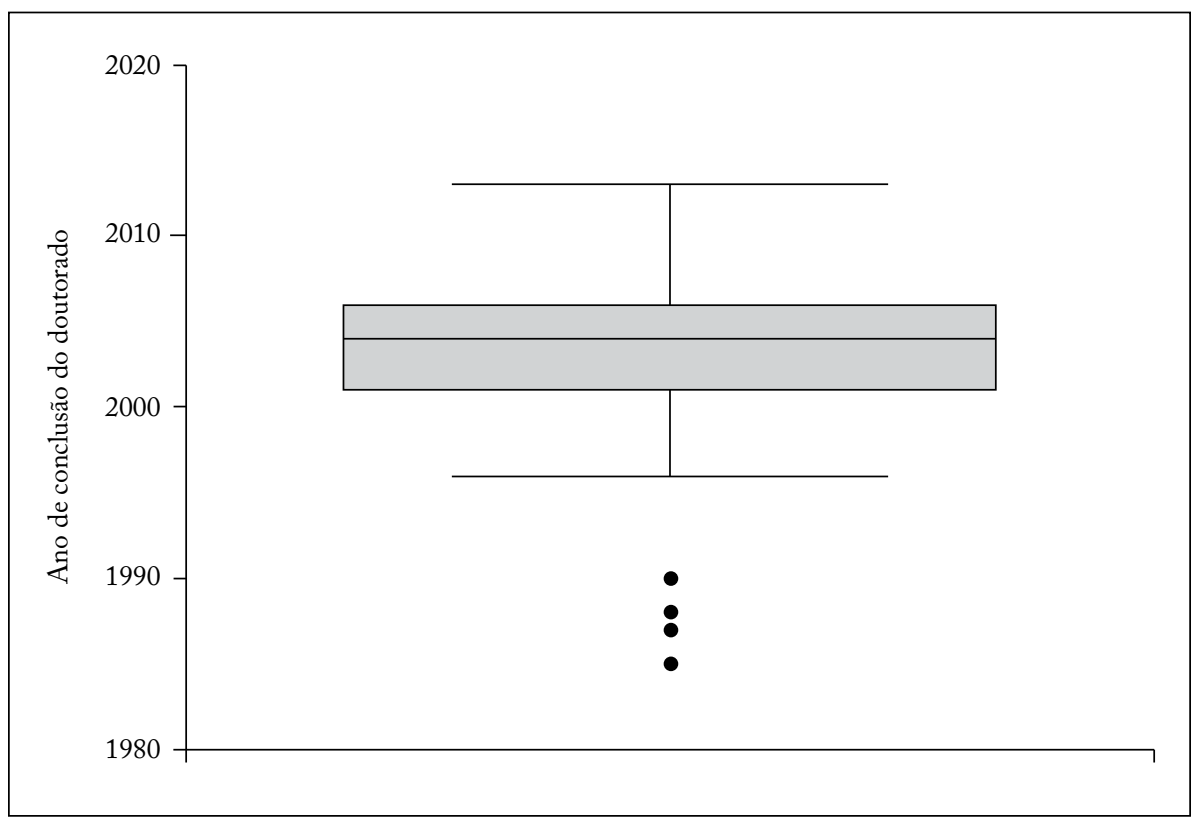

Gráfico 5 - Ano de conclusão do doutorado dos membros de coordenação (2016).

Fonte: elaboração própria. 
$\mathrm{Na}$ formação no plano de pós-doutorado, também foi concedida prioridade ao Brasil. Mais de 50\% dos respondentes que fizeram pós-doutorado $(55,26 \%)$ concluíram em instituições brasileiras, enquanto os demais preferiram Portugal $(23,68 \%)$, Alemanha (5,26\%), EUA (5,26\%), Espanha (5,26\%) e França (5,26\%).

As cinco principais IESs brasileiras nas quais os membros de coordenação realizaram o estágio de pesquisa de pós-doutorado estão nos estados do Rio de Janeiro e São Paulo: UERJ (7,89\%), USP (7,89\%), Unicamp (7,89\%), PUC-SP (5,26\%) e UFRJ $(5,26 \%)$. Cada uma das demais IESs brasileiras responde por apenas 2,63\% dos respondentes, ou seja, uma pessoa: Faculdades EST-RS, PUC-RS, PUC-Rio, UFPR, UFSC, USF, UnB e Unisinos. Todas essas instituições estão situadas, por ordem de quantidade de IESs, nas regiões: Sudeste (UERJ,USP, Unicamp, PUC-SP, UFRJ, PUC-Rio, USF), Sul (Faculdades EST-RS, PUC-RS, UFPR, UFSC e Unisinos) e Centro-Oeste (UnB). Nenhum respondente fez pós-doutorado nas regiões Norte e Nordeste.

As IESs estrangeiras nas quais os respondentes fizeram o estágio de pós-doutorado são as seguintes, por país/instituição: Portugal — Universidade do Minho, Universidade de Lisboa, Universidade Aberta, Universidade de Coimbra, Universidade do Porto e Universidade de Évora; Alemanha - Uni Kassel e Siegen Universität; EUA - Massachusetts Institute of Technology e University of California, San Diego; Espanha - Universidad de Alcalá de Henares e Universidad de Cádiz; e França - Université Paris 8 e École des Hautes Études en Sciences Sociales.

Analisando-se os tempos de docência em pós-graduação e em coordenação de programa de pós-graduação, encontramos grande disparidade. Dos 79 membros de

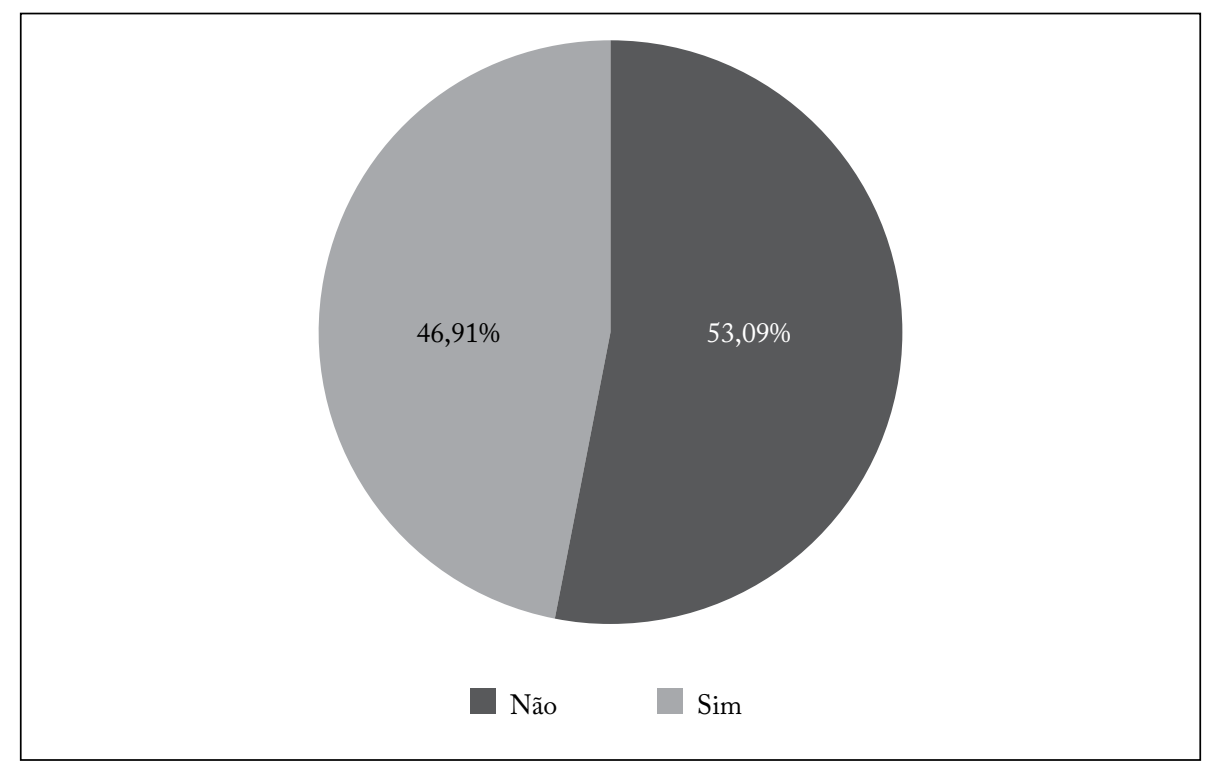

Gráfico 6 - Realização de pós-doutorado pelos membros de coordenação (2016).

Fonte: elaboração própria. 
coordenação que informaram seu tempo de docência em pós-graduação de qualquer área e, especificamente, no terreno da educação, a média aritmética de docência, no primeiro caso, corresponde a 9,34 anos, com desvio-padrão de 5,70 anos; entrementes, no segundo caso, a média aritmética é menor (8,67 anos), com desvio-padrão de 5,59 $a_{n o s}^{27}$. No tocante aos valores mínimos e máximos de tempo de docência em pós-graduação de qualquer área e, especificamente, na senda da educação, há coincidência de tempos: mínimo de um ano e máximo de 29 anos. O valor da mediana também é o mesmo nos dois casos: cerca de $50 \%$ dos respondentes possuem até 8 anos de docência; o restante tem mais de 8 anos. Observam-se três casos atípicos quanto à docência em pós-graduação de qualquer área, com valores de 24, 25 e 29 anos; e dois casos em relação à docência em PPGE, com valores de 25 e 29 anos (Gráfico 7).

Dos 77 respondentes que explicitaram o tempo de experiência como coordenador ou vice-coordenador de programa de pós-graduação em qualquer área e, especificamente, na de educação, a média aritmética é de 3,12 anos no primeiro caso, com desvio-padrão de 3,19 anos; e menor no segundo caso (2,81 anos), com desvio-padrão de 2,75 anos ${ }^{28}$. Quanto aos valores mínimos e máximos do tempo de experiência como coordenador ou vice-coordenador de programa de pós-graduação em qualquer área e, especificamente, na de educação, há coincidência desses valores:

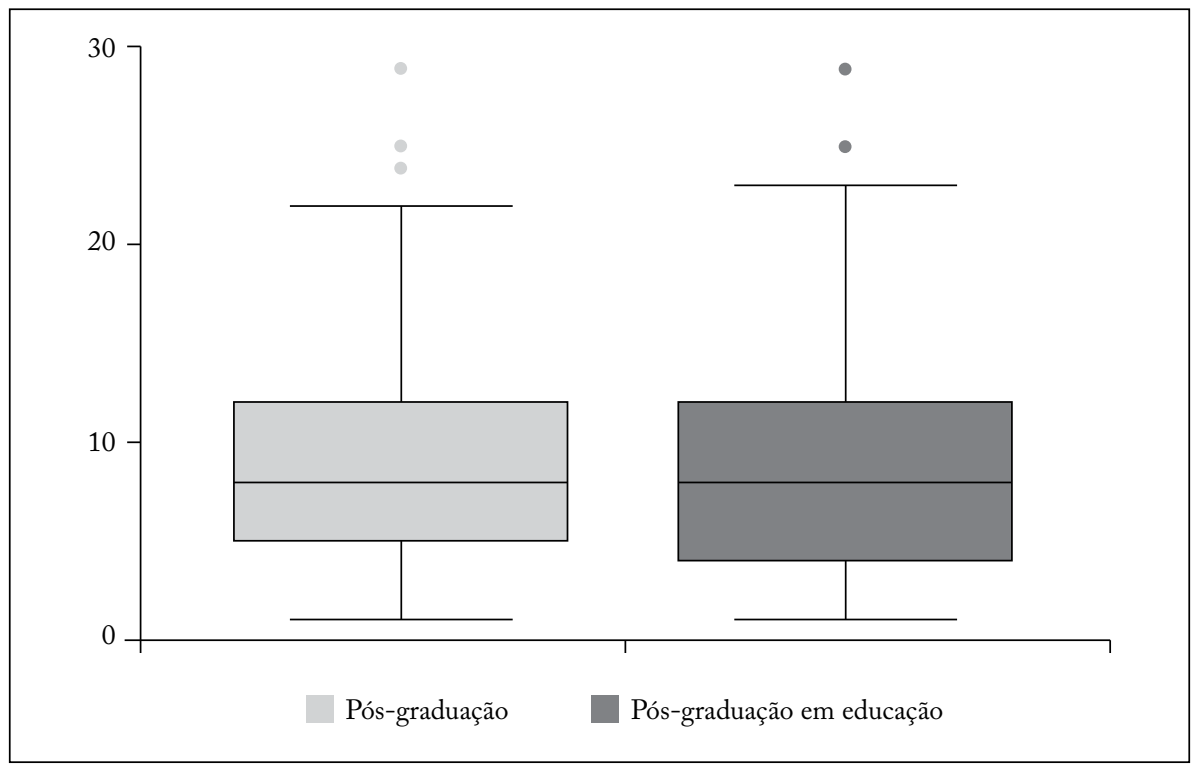

Gráfico 7 - Tempo de docência em pós-graduação de qualquer área e na de educação (2016).

Fonte: elaboração própria.

27 Esse resultado é esperado, se consideramos que um professor pode atuar em programas de outras áreas além da educação.

28 Resultado esperado, pois um professor pode assumir a coordenação de programas de outras áreas além da educação. 
existem respondentes que ainda não alcançaram 1ano de experiência na coordenação (0); enquanto o de maior tempo possui 20 anos de experiência. A mediana nos dois casos é de dois anos. Isso indicia a existência de profissionais iniciantes na função de coordenadores de programas de pós-graduação, o que sugere uma reflexão a respeito dos suportes de que dispõem, sobretudo no caso dos programas novos. Observamos dois casos atípicos quanto à experiência na coordenação de programa de pós-graduação em qualquer área, com tempos de 15 e 20 anos; e um caso, em relação a essa experiência em PPGE, com o período de 20 anos (Gráfico 8).

Se há em curso um processo de internacionalização da educação superior, destacadamente da pós-graduação stricto sensu, defendido por agências como CAPES e Conselho Nacional de Desenvolvimento Científico e Tecnológico CNPq (Marrara, 2007), é importante que os membros de coordenação também possuam alguma experiência internacional ${ }^{29}$. Mais de um quarto dos respondentes $(28,40 \%)$, todavia, ainda não tem esse tipo de experiência, exigindo medidas que contribuam para suprir essa lacuna (Gráfico 9).

Conforme se pode observar, a realização de doutorado e pós-doutorado fora do país por parte dos respondentes foi tímida. Esse fato pode ter relação com a

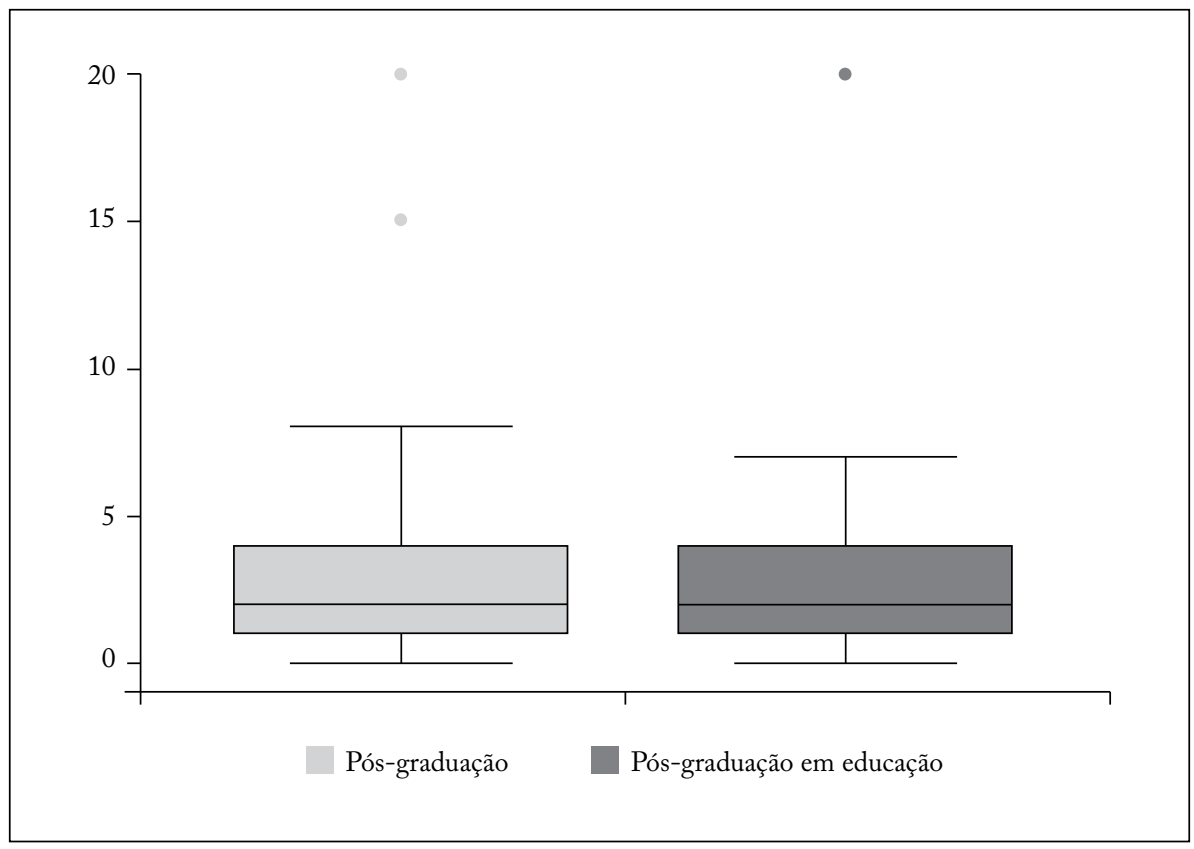

Gráfico 8-Tempo de coordenação em pós-graduação de qualquer área e na de educação (2016).

Fonte: elaboração própria.

29 Ao lado da realização de estágio de pós-doutorado, há de se considerar a existência de programas regulares e estáveis voltados para incremento da formação, pesquisa e difusão, em escala transnacional. 
proficiência que eles dizem ter em um idioma estrangeiro. Se consideramos somente os níveis "Muito bom", "Bom” e "Razoável” de proficiência, pode-se verificar que o somatório desses níveis alcança: 96,30\% (78) do total em espanhol; 70,37\% (57) em inglês; $54,32 \%$ (44) em francês; $19,75 \%$ (16) em italiano; 9,88\% (8) em alemão; e $1,23 \%$ (1) em outro idioma.

As plataformas que editam periódicos científicos são utilizadas para recepção, avaliação e publicação dos periódicos de vários programas de pós-graduação. Embora o domínio dessas plataformas seja uma exigência para os editores de periódicos, identificamos o fato de que 69,14\% (56) membros de coordenação também possuem esse domínio. Desse total, 96,43\% (54) acentuam que seu nível de domínio é "Muito bom", "Bom" ou "Razoável", enquanto os demais (3,57\%) consideram ter um nível "Muito ruim".

Com isso, temos a primeira aproximação a respeito do perfil desse coletivo que, como assinalado, se altera com alguma frequência, considerando as regulamentações de cada programa em termos de critérios para o exercício da função e a duração dos mandatos. Na sequência, procuramos observar alguns aspectos desse grupo com o próprio FORPREd.

\section{FÓRUM DE COORDENADORES DE PROGRAMAS DE PÓS-GRADUAÇÃO EM EDUCAÇÃO EM ANÁLISE}

O segundo eixo do questionário incidiu na avaliação do próprio fórum e suas dinâmicas, como recurso para diagnosticar e pensar sobre diretrizes e metas para este. Estruturado em um total de 27 questões, havia espaço destinado ao que podemos chamar de qualitativo ou inventário das posições dos coordenadores.

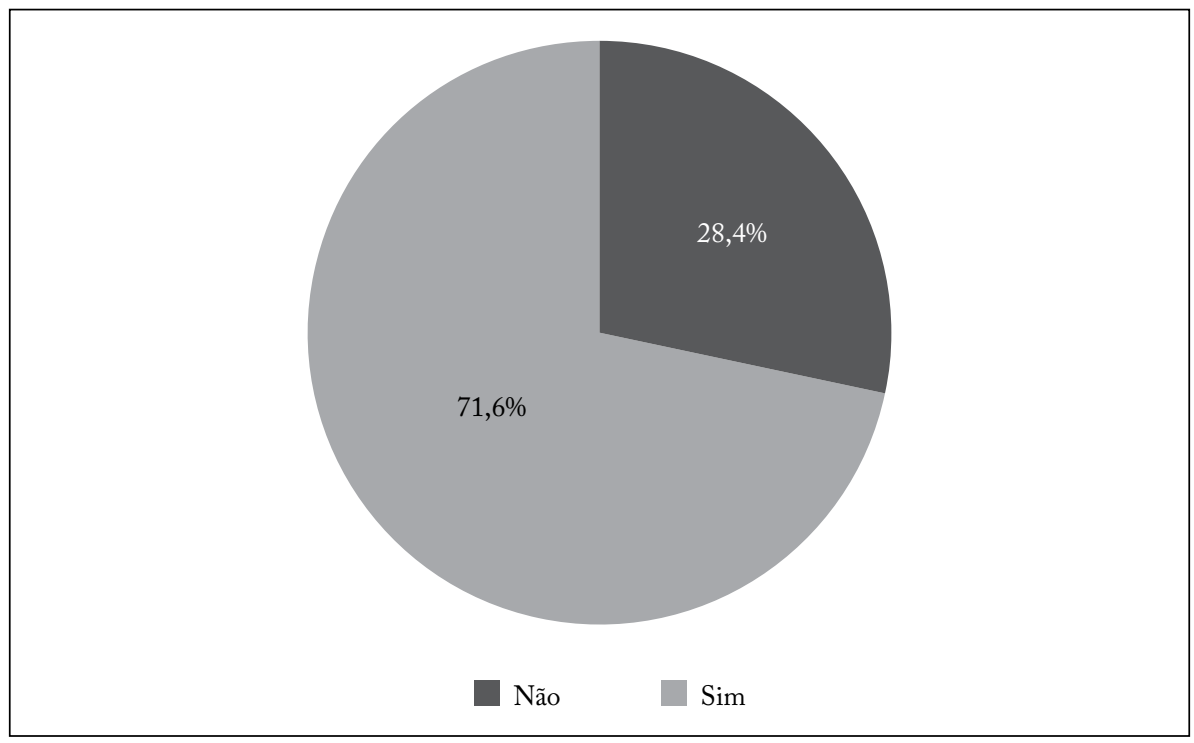

Gráfico 9 - Experiência internacional dos membros de coordenação (2016).

Fonte: elaboração própria. 
A primeira questão cuidava de mapear o grau de conhecimento do fórum por parte dos coordenares (Gráfico 10). Neste caso,33,33\% afirmaram desconhecer o FORPREd, o que demonstra consistência e alinhamento com o perfil apresentado por parte dos coordenadores. No que se refere ao contato com o FORPREd, uma resposta parece sintetizar essa aproximação. Para um dos respondentes, o conhecimento advinha de informações da antiga coordenação do programa e participação na ANPEd ou da atividade da gestão, quando lembra que, em 1995, como vice-coordenador, participara, pela primeira vez, do antigo Eduforum, que posteriormente se denominou FORPREd. Tal manifestação indica dupla modalidade de aproximação, seja pela via da associação, seja pelo caminho da gestão dos programas. Além destas, cabe destacar os debates patrocinados pelo FORPREd em torno da problemática da pesquisa, pós-graduação e avaliação, bem como o efeito da página da ANPEd na difusão do conjunto de suas atividades.

Considerando essa informação, indagamos a respeito das contribuições do fórum, solicitando que escalonassem até cinco pontos positivos, começando pelo melhor e seguindo sucessivamente. Neste caso, cabe sublinhar o reconhecimento da dimensão política do FORPREd no que diz respeito aos debates do campo, do sistema de avaliação e de articulação entre os distintos programas. Ressalta-se, também, o caráter pedagógico do FORPREd, pela via da informação, orientação e elaboração de pautas e proposições coletivas. Há destaque para o compromisso com a democratização das informações e o esforço de horizontalização das relações entre coordenadores e programas. Por fim, registramos algumas ausências de resposta para esse item, o que pode ser atribuído ao tempo dos coordenadores na função,

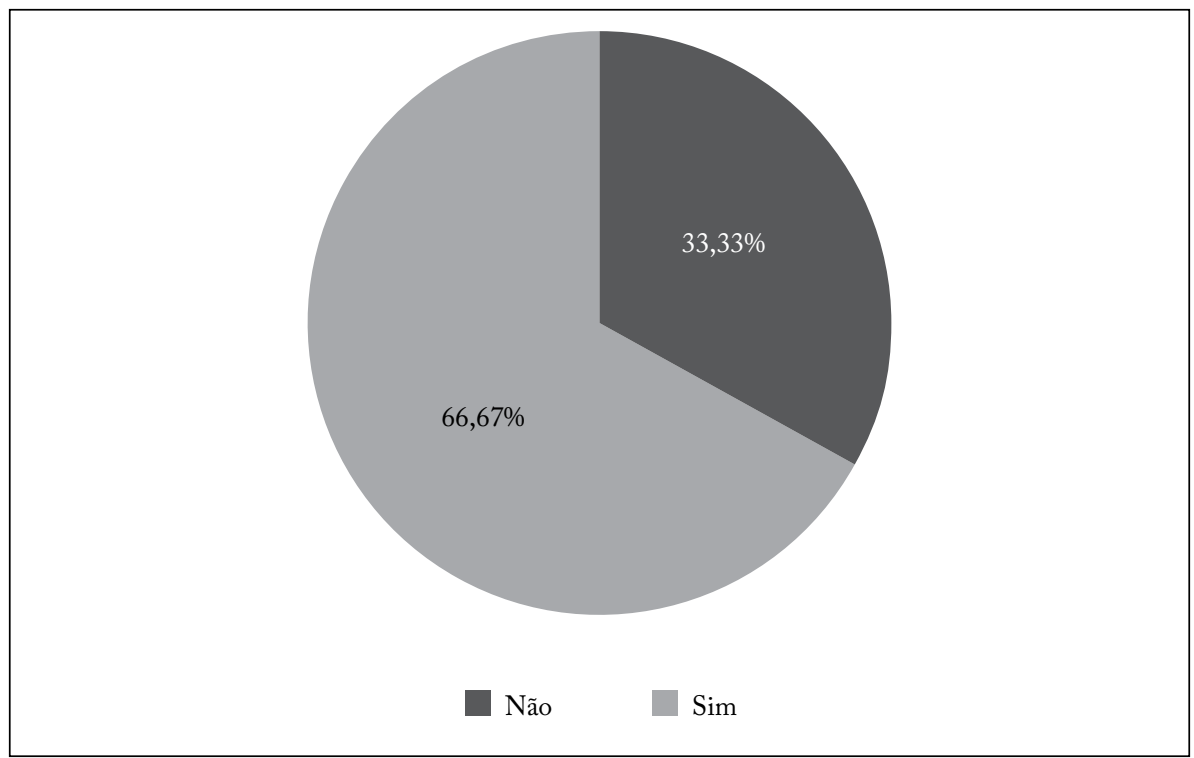

Gráfico 10 - Conhecimento sobre o Fórum de Coordenadores de Programas de Pós-Graduação em Educação antes de assumir a coordenação (2016).

Fonte: elaboração própria. 
bem como à sua relação institucional com o FORPREd, com a ANPEd e com o próprio campo da pós-graduação e pesquisa em educação.

No sentido oposto, indagamos a respeito das dificuldades enfrentadas para participar do FORPREd, escalonando até cinco dificuldades, da maior para a de menor relevância. Com foco nas que foram apontadas com recorrência como as mais relevantes, identificamos o excesso de trabalho, com as consequências no tempo dedicado ao preparo das atividades do programa. O segundo ponto diz respeito ao problema do financiamento para participar das reuniões presenciais, neste passo se criticando a alta rotatividade das coordenações, as pautas extensas e superficialidade e a fragilidade dos debates, sobretudo na lista de discussão ora em uso. Esta, por sua vez, aparece com dupla representação, a do excesso e a de que facilita a socialização de informações relevantes. No que se refere às opções para esses pontos, deduzíveis dos problemas apontados, cabe destacar a defesa de um maior uso da página da ANPEd para reunir os documentos produzidos na esfera do FORPREd, facilitar a comunicação e a montagem de uma agenda própria.

Em relação aos principais problemas e a como os membros de coordenação avaliam a dinâmica de funcionamento do FORPREd, três aspectos merecem ser destacados. $\mathrm{O}$ primeiro remete à "diversidade dos programas em educação, pois grande parte é nota 3, alguns nota 4, outros 5 e uma minoria 6 e 7" (ID29). Esse coordenador termina por indagar: "Como trabalhar um espaço de solidariedade na pós-graduação em educação já que há uma concorrência dentro da própria área?” (ID29). O outro incide na aproximação da agenda do fórum à agenda da CAPES. Por fim, a indicação da pouca (ou nenhuma) circulação da coordenação do FORPREd junto aos programas. Em conjunto, essas ocorrências sinalizam para a necessidade de se manter aberto o debate a respeito da concepção do fórum e do caráter programático que pode assumir - considerando-se as mediações entre a ANPEd, os programas e as políticas públicas, por exemplo.

No que se refere à dinâmica de funcionamento do FORPREd, 76 (93,83\%) respondentes manifestaram opinião. Destes, o Gráfico 11 indica que 75,00\% (57) dos membros de coordenação consideram "boa" ou "muito boa" a dinâmica do fórum, indicando a existência de correlação com os apontamentos anteriores, isto é, com o conhecimento sobre o fórum e suas contribuições para a gestão e políticas da área.

No concernente à política de comunicação, os respondentes desse quesito (78) mostram-se muito satisfeitos, uma vez que o percentual do somatório de "bom" e "muito bom" atingiu 78,20\% (o "razoável" foi de 11,53\%). Mesmo assim, foram feitas 22 sugestões. As três mais reiteradas são, na ordem das mais citadas: racionalizar o uso da lista de e-mails do FORPREd; produzir boletim mensal de informações, com agendas futuras do FORPREd e da ANPEd; manter o site atual do FORPREd atualizado (ou criar um espaço virtual alternativo), de modo a disponibilizar as agendas, os relatórios das reuniões e os documentos mais relevantes.

A percepção dos 81 respondentes sobre o funcionamento das "regionais" é positiva, pois $55,55 \%$ as qualificaram como "bom" e "muito bom" ("razoável": 22,22\%). Muitos(as) deram sugestões (51 pessoas) e estas devem ser mencionadas, pelo critério da recorrência superior a três citações: maior articulação das "regio- 
nais" com o FORPREd nacional; constituir maneiras opcionais de comunicação, transpondo a lista de $e$-mails; mais encontros regionais com possibilidade de participação via on-line.

Para 75,30\% dos 81 coordenadores(as) que responderam ao questionário, a relação entre o FORPREd e a ANPEd é "boa" ou "muito boa" ("razoável": 13,58\%). Apenas 13 pessoas ofereceram sugestões. Duas delas saltam à vista, com três citações cada qual, e ambas se referem à valorização do FORPREd: o fortalecimento do fórum na definição das ações da ANPEd; e o pleito para que o FORPREd seja "autônomo" em relação à entidade científica.

Nas 81 respostas sobre a relação do FORPREd com o Fórum de Editores de Periódicos da Área de Educação (FEPAE), 50,61\% avaliaram como "bom" e "muito bom" ("razoável": 27,16\%), sendo o menor percentual alcançado entre os quesitos aqui analisados. Além disso, a opção "muito bom" foi assinalada apenas por 6,17\% dos respondentes e, das 18 sugestões oferecidas, 14 continham apontamentos acerca da necessidade de maior articulação entre essas instâncias, seja por via de reuniões conjuntas, seja pelo estabelecimento de agenda e de plano de ações articulados. É patente, pois, a necessidade de maior aproximação entre FORPREd e FEPAE.

Assim como nos demais itens, $72,83 \%$ dos membros de coordenação consideraram "boa" e "muito boa" a relação do FORPREd com a coordenação da área da educação na CAPES ("razoável": 16,04\%). Foram 19 sugestões colhidas; entre elas, 6 citações ressaltaram que se deve manter e aprofundar o diálogo, com

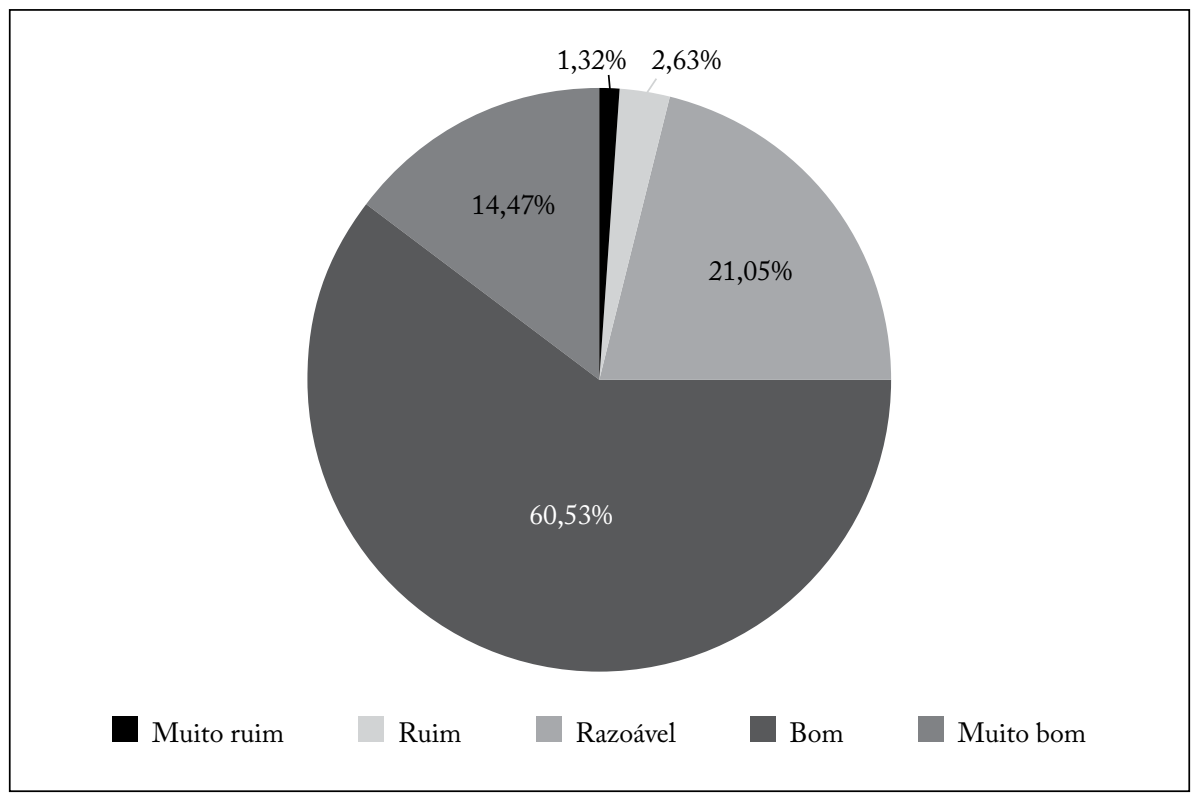

Gráfico 11 - Avaliação da dinâmica de funcionamento do Fórum de Coordenadores de Programas de Pós-Graduação em Educação (2016).

Fonte: elaboração própria. 
maior número de reuniões, preferencialmente periódicas, entre o FORPREd e a coordenação da área.

\section{A MODO DE CONCLUSÃO}

A pesquisa realizada, cujos resultados foram mostrados e analisados neste artigo, nos possibilitou conhecer aspectos da história, configurações e desafios do FORPREd desde a sua criação, em 1991. Pelo que pudemos perceber, desde sua constituição, alguns tensionamentos o marcaram, mas os membros de coordenações e seus integrantes souberam enfrentá-los, sejam os que dizem respeito à relação com a ANPEd e a CAPES, sejam os relacionados à dinâmica de funcionamento da pós-graduação.

Logo que nasceu, o FORPREd viu-se perante o dilema dos limites e das possibilidades na relação com a ANPEd, que, sobretudo, se revelava na dúvida sobre quem deveria protagonizar o diálogo com a CAPES e as demais agências de financiamento, bem como discutir e formular políticas de pós-graduação e pesquisa. Passando por inflexões em que se aventou até a possibilidade de desvincular o FORPREd da ANPEd, atualmente, todavia, como instância da associação (sócios institucionais), esse tipo de tensionamento parece ter sido reduzido no âmbito do FORPREd. Ao assumir funções específicas no interior da e com a ANPEd, como o diálogo regular e direto com a coordenação de área da educação, muitos problemas foram equacionados. Outros, no entanto, permanecem e desafiam a área como um todo.

Atualmente, o FORPREd experimenta um período de crescimento dos programas e de aumento da complexidade dos problemas por eles enfrentados. Dois deles se destacaram e se evidenciam: avaliação e financiamento. Na luta por superá-los, o modelo de avaliação estandartizado é criticado desde os anos de 1980, quando eram incipientes os instrumentos e sistemas hoje padronizados nas 49 áreas sob a coordenação da CAPES. Por sua vez, a política de financiamento não encontrou, ainda, a maneira de verter recursos com a regularidade e a quantidade necessárias, de modo a garantir a produção do conhecimento sobre educação com qualidade, com vistas a ser reconhecido nacional e internacionalmente e, em especial, influenciar de modo positivo o sistema educativo nacional.

Ainda que parte expressiva dos coordenadores seja inexperiente na função e tenha pouca vivência na pós-graduação e nas relações internacionais no âmbito da formação pós-graduada e da pesquisa, esses profissionais avaliaram positivamente a atuação da ANPEd e do FORPREd como instâncias de organização e de intervenção na política e funcionamento do sistema nacional de pós-graduação. Por fim, cabe assinalar que os desafios dos atuais coordenadores e dos integrantes dos programas da área de educação atualizam parte da tradicional agenda desses coletivos, de modo a enfrentar a difícil equação que entrecruza o eixo da expansão com novas modalidades de formação pós-graduada com a necessária exigência de financiamento sustentável e também regular, com vistas a assegurar a qualidade da formação, do que se pesquisa, se ensina e se divulga em termos de conhecimento socialmente desejável. 


\section{REFERÊNCIAS}

Associação Nacional de Pós-Graduação e Pesquisa em Educação (ANPEd). Estatuto da Associação Nacional de Pós-Graduação e Pesquisa em Educação - ANPEd. Rio de Janeiro, 2012. Disponível em: <http://www.anped.org.br/sites/default/files/ estatuto_anped_registro_cartorio_.pdf $>$.Acesso em: 20 fev. 2017.

Babbie, E. Métodos de pesquisas de survey. Belo Horizonte: Ed. UFMG, 1999.

Bauer, M. W. Análise de conteúdo clássica. In: .; Gaskell, G. Pesquisa qualitativa com texto, imagem e som: um manual prático. Petrópolis, RJ: Vozes, 2002. p. 189-217.

Bianchetti, L. Os dilemas do coordenador de programa de pós-graduação: entre o burocrático-administrativo e o acadêmico-pedagógico. In: .; Sguissardi, V (Org.). Dilemas da pós-graduação. Campinas: Autores Associados, 2009. p. 15-99.

Boletim ANPEd. Rio de Janeiro: ANPEd, v. 1, n. 1, jan./fev. 1979. Disponível em: $<$ http://anped.org.br/sites/default/files/boletim_anped_v._1_n._1.pdf >. Acesso em: 20 fev. 2017.

Boletim ANPEd. Rio de Janeiro: ANPEd,v. 3, n. 1, out. 1981. Disponível em: <http:// anped.org.br/sites/default/files/boletim_anped_v.3_n.1_out.1981.pdf >. Acesso em: 20 fev. 2017.

Boletim ANPED. Rio de Janeiro: ANPEd,v. 7, n. 4, ago. 1985. Disponível em: <http:// anped.org.br/sites/default/files/boletim_anped_v.7_n.4_ago.1985.pdf>. Acesso em: 20 fev. 2017.

Calazans, J. ANPEd - Trajetória da pós-graduação em pesquisa em educação no Brasil. Belo Horizonte: Documentos ANPEd, 1995.

Fávero, L. P.; Belfiore, P.; Takamatsu, R. T.; Suzart, J. Métodos quantitativos com Stata. Rio de Janeiro: Elsevier, 2014.

Johnson, B.; Christensen, L. B. Educational researcb: quantitative, qualitative, and mixed approaches. $2^{\text {nd }}$ ed. Boston: Allyn \& Bacon, 2003.

MARrara, Thiago. Internacionalização da pós-graduação: objetivos, formas e avaliação. R B P G, Brasília, v. 4, n. 8, p. 245-262, dez.2007. Disponível em: <http://ojs.rbpg.capes. gov.br/index.php/rbpg/article/view/132/126>. Acesso em: 20 fev. 2017.

Puccı, B. Fórum dos Coordenadores de Programas de Pós-Graduação em Educação: apontamentos históricos. Revista Brasileira de Educação, v. 12 n. 36, set./dez. 2007, p. 424-547. Disponível em: <http://www.scielo.br/pdf/rbedu/v12n36/a04v1236.pdf>. Acesso em: 09 nov. 2016.

Saviani, D. A Pós-Graduação em Educação no Brasil: trajetória, situação atual e perspectivas. Revista Diálogo Educacional, v. 1, n. 1, p. 1-95, jan./jun.2000. Disponível em: $<$ http://www2.pucpr.br/reol/pb/index.php/dialogo?dd1=703\&dd99=view\&dd98=p>. Acesso em: 20 mai. 2017.

WRIGHT, K. B. Researching internet-based populations: advantages and disadvantages of online survey research, online questionnaire authoring software packages, and web survey services. Journal of Computer-Mediated Communication, v. 10, n. 3, abr. 2005. 
Anexo 1 - Boletins da ANPEd (1979-1990) ${ }^{30}$.

\begin{tabular}{|l|c|c|c|c|c|}
\hline & Vol. & $\mathrm{N}^{\mathbf{0}}$ & Meses & Anos & Pág. \\
\hline 1 & 1 & 1 & Jan./fev. & 1979 & 8 \\
\hline 2 & 1 & 2 & Mar./abr. & 1979 & 12 \\
\hline 3 & 3 & 1 & Out. & 1981 & 10 \\
\hline 4 & 3 & 2 & Nov./dez. & 1981 & 10 \\
\hline 5 & 4 & 1 & Fev. & 1982 & 12 \\
\hline 6 & 4 & 6 & Ago. & 1982 & 4 \\
\hline 7 & 4 & 7 & Set./out. & 1982 & 7 \\
\hline 8 & 4 & 8 & Nov./dez. & 1982 & 8 \\
\hline 9 & 5 & 2 & Maio & 1983 & 7 \\
\hline 10 & 5 & 9 & Mar. & 1983 & 8 \\
\hline 11 & 7 & 1 & Jan. & 1985 & 10 \\
\hline 12 & 7 & 2 & Fev. & 1985 & 7 \\
\hline 13 & 7 & 3 & Jul. & 1985 & 16 \\
\hline 14 & 7 & 4 & Ago. & 1985 & 16 \\
\hline 15 & 7 & 5 e 6 & Out./dez. & 1985 & 36 \\
\hline 16 & 8 & 1 & Jan./mar. & 1986 & 36 \\
\hline 17 & 8 & 2 & Abr./jun. & 1986 & 36 \\
\hline 18 & 8 & 3 e 4 & Jul./dez. & 1986 & 92 \\
\hline 19 & 9 & 1 & Jan./mar. & 1987 & 62 \\
\hline 20 & 12 & 1 e 2 & Jan./dez. & 1990 & 93 \\
\hline
\end{tabular}

Anexo 2 - Coordenadores e vice-coordenadores do Fórum de Coordenadores de Programas de Pós-Graduação em Educação.

\begin{tabular}{|l|c|}
\hline Coordenadores/Vice-Coordenadores & Períodos \\
\hline Neidson Rodrigues (UFMG)//José André Angotti (UFSC) & abr. 1993/set. 1993 \\
\hline Mirian Jorge Warde (PUC-SP)/Robert Verhine (UFBA) & set. 1993/set. 1995 \\
\hline Jacques Therrien (UFC)/Elisabeth Silveira (UERJ) & set. 1995/set. 1997 \\
\hline Jésus de Alvarenga Bastos (UFF)/Maria Célia Marcondes de Moraes (UFSC) & set. 1997/set. 1998 \\
\hline Eunice Trein (UFF)/Valeska Fortes de Oliveira (UFSM) & set. 1998/set. 1999 \\
\hline Vera Maria de Sousa Nigro Placo (PUC-SP)/Marcos Villela Pereira (UFPEL) & set. 1999/set. 2000 \\
\hline José Pedro Boufleuer (UNIJUI)/Marcos Corrêa da S. Loureiro (UFG) & set. 2000/set. 2002 \\
\hline $\begin{array}{l}\text { Antônio Carlos do Nascimento Osório (UFMS)/Rita Vieira de Figueiredo (UFC) } \\
\text { *Rita Vieira de Figueiredo (UFC) foi substituída por Luis Carlos Sales (UFPI) } \\
\text { em out. 2003 }\end{array}$ & set. 2002/nov. 2004 \\
\hline Anete Abramowicz (UFSCar)/Ronaldo Lima (UFPA) & 2004/2006 \\
\hline
\end{tabular}

Continua...

30 O levantamento e fichamento dos Boletins da ANPEd foi realizado pela doutoranda Edgleide de Oliveira Clemente da Silva (UERJ/PROPEd), bolsista da FAPERJ, a quem agradecemos pelo cuidadoso trabalho efetivado. 
Anexo 2- Continuação.

\begin{tabular}{|l|c|}
\hline Coordenadores/Vice-Coordenadores & Períodos \\
\hline Sílvio Gallo (UNICAMP)/Maria Clara Bueno Fischer (UNISINOS) & $2006 / 2008$ \\
\hline Adelaide Alves Dias (UFPB)/Alice Casimiro Lopes (UERJ) & $2008 / 2010$ \\
\hline Alice Casimiro Lopes (UERJ)/Fabiany de Cássia Tavares Silva (UEMS) & $2010 / 2012$ \\
\hline $\begin{array}{l}\text { Jefferson Mainardes (UEPG)/Alfredo Macedo Gomes (UFPE) } \\
\text { *Alfredo Macedo Gomes (UFPE) foi substituído por Marcia Santos Ferreira } \\
\text { (UFMT) em 2013 }\end{array}$ & $2012 / 2014$ \\
\hline Marcia Santos Ferreira (UFMT)/Samuel Mendonça (PUC-Campinas) & 2014/out. 2015 \\
\hline José G. Gondra (UERJ)/João Batista Carvalho Nunes (UECE) & out. 2015/out. 2017 \\
\hline
\end{tabular}

Fonte: elaboração própria.

\section{SOBRE OS AUTORES}

José Gonçalves Gondra é doutor em educação pela Universidade de São Paulo (USP). Professor da Universidade do Estado do Rio de Janeiro (UERJ). E-mail: gondra.uerj@gmail.com

João Batista Carvalho Nunes é doutor em filosofia e ciências da educação pela Universidad de Santiago de Compostela (Espanha). Professor da Universidade Estadual do Ceará (UECE).

E-mail: joao.nunes@uece.br

Marcos Francisco Martins é doutor em educação pela Universidade Estadual de Campinas (Unicamp). Professor da Universidade Federal de São Carlos (UFSCar).

E-mail: marcosfranciscomartins@gmail.com

Recebido em 2 de agosto de 2017 Aprovado em 6 de fevereiro de 2018 